\title{
TERRITÓRIOS DA COZINHA SOB A ÓTICA DE EMPREGADAS DOMÉSTICAS
}

\author{
Felipe Gouvêa Pena \\ Mestre em Administração \\ Universidade Federal de Minas Gerais \\ Belo Horizonte - Minas Gerais - Brasil \\ felipegouveap@hotmail.com \\ Luiz Alex Silva Saraiva \\ Doutor em Administração \\ Universidade Federal de Minas Gerais \\ Belo Horizonte - Minas Gerais - Brasil \\ saraiva@face.ufmg.br
}

\section{RESUMO}

As cozinhas domésticas recentemente têm sido ressignificadas, em razão de aspectos arquitetônicos e midiáticos que lhes destinam a função de espetacularização da preparação de alimentos, silenciando sobre diversas dimensões associadas ao cozinhar. Para problematizar este quadro, o objetivo aqui é identificar e analisar os territórios da cozinha sob a ótica de empregadas domésticas, o que foi feito por meio do método indutivo com base em um estudo qualitativo de caráter descritivo, no qual foi usada a fotoelicitação para a coleta de dados e a análise do discurso para tratar das falas de empregadas domésticas. Os principais resultados sugerem territórios marcados em razão de diferentes elementos. Encontramos diferentes formas de apropriação e diferentes argumentos que as sustentam, como a "cozinha de verdade", em que cozinhar se relaciona a uma obrigação, e a um cotidiano muitas vezes de melancolia e tristeza; a "cozinha moderna" como espaço de status social e distinção; a "cozinha bem montada" enquanto espaço de prazer e alegria; e a "cozinha como vitrine", possibilitando a autopromoção por meio da exposição. As empregadas domésticas buscaram se afastar de algumas imagens e se aproximar de outras, como se tentassem compreender qual o território que se assemelhava às suas vivências e seus desejos. As principais implicações do estudo apontam a necessidade de politizar espaços aparentemente neutros, tais como a cozinha, e encará-los também sob a ótica de produção social de desigualdades de raça, sexo e trabalho, ampliando os diálogos da interseccionalidade no campo dos Estudos Organizacionais.

Palavras-chave: Cozinha doméstica; Empregadas domésticas; Relações sociais; Territorialidades.

\section{KITCHEN TERRITORIES UNDER DOMESTIC EMPLOYEES' POINT OF VIEW}

\begin{abstract}
Domestic kitchens have recently been renamed in terms of architectural and mediatic aspects that assign the show of food preparation, silencing several dimensions associated with cooking. To discuss this framework, our objective is to identify and analyze kitchen territories under the domestic servants' perspective. Starting from a structural epistemology, this research study was conducted using inductive method based on a qualitative and descriptive approach, in which photo elicitation data were collected and discourse analysis used to deal with maids' speeches. Main results suggest territories marked by different elements. We found different forms of appropriation and different arguments that support them, such as "real kitchen", in which cooking is related to an obligation, and to an often melancholic and sad daily life; "modern kitchen" as a space of social status and distinction; "well-assembled kitchen" as a space of pleasure and joy; and "kitchen as a showcase", enabling self-promotion through the exhibition. Domestic servants sought to move away from some images and approach others, as if trying to understand which territory resembled their experiences and desires. Main implications suggest politicize seemingly neutral spaces, such as the kitchen, also perceive them from the point of view of social production of race, sex and work inequalities, highlighting dialogues of intersectionality in Organizational Studies field.
\end{abstract}

Keywords: Territorialities; Social relationships; Domestic kitchen; Maids. 


\section{INTRODUÇÃO}

Em uma cultura patriarcal, racista e classista como a brasileira, a cozinha sempre foi um espaço destinado aos "inferiores estruturais", sejam eles escravos, empregadas domésticas e mulheres, enquanto donas de casa: "[...]um espaço rigidamente separado das áreas públicas e sociais da casa e interditado aos olhares de estranhos" (Barbosa, 2012, p. 188). Apesar do historicamente notório interesse em manter essa parte da casa e seus integrantes afastados, estrutural e simbolicamente, como se fossem desprovidos de valor quaisquer aspectos relacionados a esse espaço, a cozinha e o ato de cozinhar vem sofrendo ressignificações. Observa-se atualmente uma intensa exposição midiática da cozinha em diversos programas de televisão, revistas, sites, blogs, eventos de gastronomia, além de um forte posicionamento da indústria arquitetônica e de fabricantes de utensílios, todos vendendo a ideia de uma "nova" cozinha e de "novos donos". Este processo vem dando aos homens um status diferenciado em discursos que os qualificam como "chefs" e lhes pedem para cozinhar em momentos oportunos, quando a expectativa é de aplauso e a atividade se torna um espetáculo.

Tal valorização da cozinha, dos sujeitos e de todo o processo de "gastronomização" do cotidiano alimentar (Barbosa, 2012) silencia processos de exclusão, de marginalização e de preconceito diante de relações sociais de sexo e raça. A disposição desse espaço, tomado aqui como um território, ante a dinâmica de apropriação, não se refere apenas a um reduto em que ocorre a materialização das interações sociais, pois ela própria tende a estruturar tais interações. Não é possível falar em neutralidade na cozinha doméstica. Ela é demarcada política e ideologicamente, sendo palco, em diferentes instâncias, das coerções do grupo de dominantes, frente ao dos dominados socialmente (Lefebvre, 1991).

Nesse sentido, embora possa causar estranheza inicial problematizar a cozinha, entende-se que se trata de parte da esfera organizacional, uma vez que, nesse espaço, observam-se relações sociais de sexo e de raça semelhantes às de qualquer outro espaço "corporativo", chamando atenção para o debate interseccional, além das notórias noções de "planejamento", "organização", "direção" e "controle" de muitos aspectos do cotidiano desse ambiente. O fenômeno social de que tratamos, observando a cozinha, tem espelhamento em outros espaços organizacionais, o que qualifica este espaço para uma discussão também no âmbito dos Estudos Organizacionais. Além disso, realizar a discussão com base na interseccionalidade permite que se apreenda a articulação das múltiplas diferenças e desigualdades vivenciadas no território em questão, por meio de diferentes ferramentas analíticas (Piscitelli, 2008).

Este artigo tem como objetivo identificar e analisar os territórios da cozinha sob a ótica de empregadas domésticas. As vivências dessas mulheres fazem parte da problematização aqui levantada, e seus relatos trazem à tona uma série de questões relativas à dinâmica territorial da cozinha doméstica. Além dessa breve contextualização, um aprofundamento deste artigo é feito em outras seis seções, sendo elas três seções teóricas sobre territorialidades, relações sociais de sexo e as relações sociais de raça, a metodologia, a análise dos resultados e as considerações finais.

\section{TERRITORIALIDADE, TERRITORIALIDADES}

O espaço pode ser compreendido como o produto das ações dos homens sobre si mesmos, considerando a intermediação dos objetos, naturais ou artificiais, que o circundam. Trata-se do conjunto indissociável de sistemas de ações e objetos, em que, de um lado, os sistemas de ações determinam a manutenção de novos ou preexistentes objetos e, de outro, percebe-se que os sistemas de objetos definem a forma como se estabelecem as ações (Santos, 2008). Todo o processo de configuração e de transformação de tal espaço deve ser visto como um movimento contínuo e dinâmico, já que é fruto de um conjunto de relações sociais. Assim, não é plausível reduzir a análise à dimensão física e às condições naturais, pois o espaço de antemão implica a noção de vida social (Lefebvre, 1992). 
Como recorte teórico dos estudos sobre espaço, Santos (2008) apresenta a análise das configurações territoriais como uma possibilidade de investigação. Segundo o autor, a dimensão territorial é oferecida pelo somatório das condições naturais existentes naquela área e dos aditamentos impostos pelos indivíduos a estes sistemas naturais. Nesses termos, o território pode ser definido como um espaço apropriado por direito, contido, legitimado ou mesmo controlado por um grupo específico ou instituição, a partir de práticas simbólicas que tipificam uma determinada "afetividade" (Saraiva, Carrieri \& Soares, 2014). Por conseguinte, pode-se dizer que o "[...]território é, antes de tudo, o espaço no qual se enraíza nossa identidade, o lugar de nossos prazeres, de nossos temores, de nossas relações importantes, a superfície de inscrição de nossa história pessoal, enfim o conjunto de nosso sistema de referência" (Pàges et al., 1987, p. 119). Dadas as possibilidades plurais dos sistemas de referência pessoais, um território pode abrigar múltiplas territorialidades.

Nessa perspectiva, alguns pesquisadores passaram a "[...]investigar a constituição de territorialidades distintas como forma de adensar a compreensão da dinâmica transescalar e multidimensional do mundo contemporâneo" (Paula, 2011, p. 106). O pressuposto de formação de um espaço geralmente se encontra associado à noção de território, pois percebe-se que essa formação ocorre assim que o espaço passa a ser apropriado, real ou simbolicamente, por um sujeito ou grupo de individuos. Dessa forma, não é o bastante que "o espaço geográfico" esteja em um contexto de interações sociais e que seus sentidos, funções e significados sejam modificados; é preciso que ocorra uma relação de posse e de apropriação para que seja tomado como território (Bernardo, 2015). Assim, enquanto a espacialidade implica concretude, a territorialidade amplia essa perspectiva, incorporando o simbólico ao concreto. Um mesmo espaço, assim, pode ser apropriado, simultaneamente ou não, de muitas formas diferentes

Para Pereira e Carrieri (2005), a organização, quando tomada como território, possibilita a construção de "significações culturais" e, ao mesmo tempo, de "identidades" que, ao serem atribuídas pelos grupos organizacionais, materializam um controle simbólico sobre esse território. Portanto, "[...]o uso cotidiano dos espaços simbólico e físico pertencentes a cada grupo organizacional seria um exemplo claro das transformações nas significações culturais, da transfiguração das relações de dominação e de submissão existentes em quaisquer organizações" (Pereira \& Carrieri, 2005, p. 4). Nesses termos, entende-se que a transformação de determinada organização está associada aos processos de bricolage dos atores sociais que se apropriam do espaço e o convertem em território.

Agnew (1994) alega que a territorialidade humana deveria ser assumida como algo estratégico, por meio da qual os coletivos ou mesmo seus indivíduos, exercem o controle sobre um determinado espaço que foi demarcado e tomado como território. A territorialidade aqui pode ser vista como um caso próprio de espacialidade, pois, há uma conglomeração de diferentes formas, objetivas e subjetivas, de se relacionar com o espaço em questão, uma vez que a territorialidade estaria focada nos efeitos das relações sociais, atentando para significados de poder mediando o jogo de apropriação e exclusão. Ao longo dos tempos, nas diferentes sociedades, criaram-se formas próprias de caracterizar a territorialidade, podendo elas serem exercidas por meio da aceitação comum de hierarquização de um dado espaço, criando distinções entre os territórios; por meio da comunicação estabelecida entre os sujeitos, evidenciada a partir dos significados extraídos da colocação dos marcos e limites; e por meio do controle forçado, o que refletiria uma dinâmica de submissão (Agnew, 1994).

Para Paula (2011), a territorialidade usualmente cita dinâmicas e características de um dado grupo que vive no território, como sentimentos de pertencimento, desenvolvimento de identidades diversas e apropriações. Assim, associa-se à "dimensão vivida" conforme incorpora fatores que são visualizados nas relações entre os sujeitos e os espaços. Chama-se aqui a atenção para a possibilidade de que a territorialidade seja vista como o "qualitativo de qualquer fenômeno" no âmbito territorial, seja em qual escala ele estiver inserido. Nesse sentido, seria possível presenciar a sobreposição de territorialidades formais (emanadas do poder público) frente às territorialidades 
subjetivas (de todo o tipo de coletivo mobilizado), refletindo no fato de que a variável subjetiva está alicerçada na maneira como os grupos vivenciam e concebem cada espaço (Paula, 2011).

De acordo com Raffestin (1993), a territorialidade assume um valor particular, pois espelha a "multidimensionalidade" do que é vivido no território. Assim, os homens vivem, simultaneamente, o processo e o produto territorial a partir de um sistema de relações produtivas e/ou existenciais. Cabe notar que, independentemente de quais sejam as relações, todas elas são, categoricamente, relações de poder orquestradas pelos atores sociais (Raffestin, 1993; Saraiva, Carrieri \& Soares, 2014). Tais pressupostos sobre territorialidade transcendem os contextos, podendo se considerar tanto o âmbito público quanto o privado.

Observando especificamente a cozinha doméstica do ponto de vista territorial, são necessárias algumas reflexões sobre a casa e a cozinha em si, enquanto locais de contradição. Maia (2012) afirma que é indispensável um olhar atento aos significados atribuídos a esse território vivo, relacional e singular por cada sujeito. A casa carrega um valor simbólico e concreto, mas, para os indivíduos mais pobres, ela pode representar muito mais como, por exemplo, ser um elemento apto de torná-los a serem reconhecidos como autores de suas próprias histórias. A casa também é fundamental para a sociedade, já que atesta a reprodução social e indica relações de consumo. Assim, como a cozinha, a casa é palco histórico de interações sociais entre sexos e raças, o que vem passando por ressignificações do ponto de vista concreto e simbólico em meio a discursos midiáticos de reapropriação territorial.

Para Lefebvre (2008), considerando que o espaço envolve o tempo, é necessário admitir que, no mundo das mercadorias, o que está em jogo não é apenas a aquisição de um espaço repleto de signos de hierarquia social e prestígio. Ao adquirir um espaço, estabelece-se uma distância entre os que o possuem e os que não o possuem. Os "espaços-tempos", referenciados por Henri Lefebvre, se relacionam diretamente à reprodução de um conjunto complexo de relações sociais que reiteram o estabelecimento de limites territoriais. Maia (2012) assegura que há uma fluidez entre as dimensões do público e do privado, mas ambas se relacionam e espelham as relações entre os sujeitos. A casa e a rua estão interligadas, sendo a porta da residência a primeira demarcação fronteiriça. No entanto, existem também fronteiras internas que dividem a casa e concedem a cada sujeito a posse de um espaço, que ele pode assumir ou não, a exemplo da cozinha, historicamente tida como um reduto feminino. A apropriação sugere que a territorialidade se inclui em uma dinâmica relacional, expressando "[....] a consciência dos sujeitos, sua intencionalidade, forjando sua identidade e demarcando sua diferença/distinção em relação ao outro" (Maia, 2012, p. 346), o que também inclui as relações sociais de sexo e raça que ali se apresentam.

\section{RELAÇÕES SOCIAIS DE SEXO}

No capitalismo, o primeiro contingente feminino a ser marginalizado foi o das esposas dos membros da classe burguesa ascendente. Entretanto, para Saffioti (2013), a sociedade definitivamente não prescinde do trabalho das mulheres ditas de camadas inferiores. Muito pelo contrário, a marginalização e inferiorização social que as mulheres sofreram, desde muito tempo, veio a favorecer o aproveitamento dessa população feminina no trabalho industrial. O núcleo de desvantagens sociais a que as mulheres estavam sujeitas permitia ao sistema capitalista extrair o máximo possível de mais-valia absoluta por meio da "[....]intensificação do trabalho, da extensão da jornada de trabalho e de salários mais baixos do que os masculinos, uma vez que, para o processo de acumulação rápida de capital, era insuficiente a mais-valia relativa obtida através do emprego da tecnologia de então" (Saffioti, 2013, p. 67). Embora a máquina do capital já tivesse elevado muito a produtividade do trabalho, não havia saciado a sede da classe burguesa pelo seu enriquecimento a qualquer custo.

Os princípios de separação e hierarquização, que contribuíram para a divisão sexual do trabalho, puderam ser vistos em várias sociedades ao longo da história, sendo tomados como legítimos no tempo e no espaço. "Podem ser aplicados mediante um processo específico de 
legitimação, a ideologia naturalista. Esta rebaixa o gênero ao sexo biológico, reduz as práticas sociais a 'papeis sociais' sexuados que remetem ao destino natural da espécie" (Hirata \& Kergoat, 2007, p. 599). Nesse contexto, a dimensão do trabalho doméstico talvez possa ser compreendida como a base dessa segmentação. No entanto, essa problematização pode ser feita de uma forma mais efetiva: afinal, ao invés de tomar o conceito do trabalho doméstico para questionar a estrutura de uma sociedade salarial, usam-se a termos como "dupla jornada", "conciliação de tarefas" ou "acúmulo", como se fossem apêndices por excelência de um trabalho assalariado - silenciando a desigualdade nas relações e potencializando a naturalização dos papeis sociais conforme o sexo.

É preciso esclarecermos que a opção pelo uso do termo "relações sociais de sexo" em detrimento da expressão "relações sociais de gênero", corrobora os pressupostos de Devreux (2005). Conforme a autora, em uma sociedade marcada pelos desdobramentos do patriarcado, é basilar questionar os critérios de hierarquização do sujeito desde o seu nascimento. Portanto, a primeira classificação social diz respeito ao "sexo" e não ao gênero; o segundo é constituído e o primeiro é demarcado. Para os propósitos deste artigo, não compreender essa distinção seria um erro, pois silenciaria muitas questões do ponto de vista epistemológico.

Para Neves (2013, p. 409), a responsabilidade pelo trabalho doméstico foi reforçada como algo "natural" para as mulheres, tendo a aprendizagem ocorrido muitas vezes na própria família, somando-se a isso a "[...]naturalização e a desvalorização dos processos de aquisição de competências que ocorrem fora das instituições formais". No âmbito de tais relações domésticas, a cozinha talvez seja o exemplo mais claro da divisão por sexo dentro da casa. Conforme já ressaltava Heredia (1979), embora a residência seja tomada como um espaço da mulher, nela há espaços mais femininos e mais masculinos. A autora chama a atenção para o fato de que a "sala" foi associado à esfera do masculino, ao passo que a "cozinha" foi tida como um reduto feminino por excelência. Historicamente esse ambiente ficava no fundo das moradias, como se parte de algo que fosse dispensável dar valor, seja por abrigar a cozinheira, normalmente negra, seja por abrigar cotidianamente a dona de casa. A ideia de que a cozinha doméstica sempre foi o lugar da mulher deixou encoberta uma série de relações de preconceito, exclusão, marginalização e sofrimento.

Como bem sintetizado por Pagès et al. (1987, p. 70), a organização do trabalho se constitui não apenas diante dos pilares da racionalidade, mas também em meio a construções simbólicas "autorizadas" por essa racionalidade. O mais fortuito desse processo decorre da capacidade que esse sistema possui de lançar mão de referências ideológicas tradicionais para amparar "[...]a instauração de estruturas abstratas da vanguarda do capitalismo. Estas construções simbólicas conferem ao sistema de regras o estatuto de sistemas de produção. $\mathrm{O}$ respeito às regras aparece necessário à sobrevivência tanto do indivíduo como da estrutura que o sustenta". Entre elas, destaca-se a ideologia sexista.

Admite-se, como Saffioti (2004), que a ideologia sexista, de um polo ao outro da relação dominação-subordinação, corporifica-se nos agentes sociais que fazem parte desse sistema. Para a autora, o sentido figurado que se adota ao falar em "corporificação de ideologias" de modo geral, e em específico no caso da ideologia sexista, pode ser percebido no vínculo que arbitrariamente é estabelecido entre o que ela denomina de fenômenos. Para ela, a voz grave atesta um nível de poder. De forma muito singular, Saffioti (2004, p. 124) faz essa associação ao tom de voz do homem em relação ao da mulher, traçando um paralelo com a ideia de categoria social e o sistema capitalista: "A voz grave do assalariado não o empodera diante de seu patrão, pois o código na estrutura de classes é outro".

Nesse cenário, Pinto, Nunes e Fazenda (2014) indicam que é por meio da observação das diferenças sexuais que a sociedade acaba por enquadrar as tarefas sob responsabilidade de homens e de mulheres como representações sociais. Porém, essa visão simplista e discriminatória termina por não considerar as individualidades. Desse modo, constroem-se as relações de sexo, considerando o feminino e o masculino como opostos e, ao mesmo tempo, complementares. Ao adicionar outras dimensões, tal como a raça, a discussão se torna ainda mais densa, pois a hierarquização no 
trabalho, por exemplo, parece seguir uma lógica, de primeiro os homens, desde que sejam brancos, e depois as mulheres, desde que não sejam negras.

Diante dessas questões, Carneiro (2003) afirma que existe a necessidade de articular questões de gênero e raça, pois a história indica que a "variável" racial foi capaz de produzir gêneros subalternizados, seja em relação à estigmatização da "identidade feminina" (das mulheres negras), ou como "masculinidades inferiorizadas" (dos homens negros), ao possuírem menor "prestígio" do que o gênero feminino do grupo racial oposto (as mulheres brancas). Percebe-se então uma hierarquização: homens brancos, mulheres brancas, homens negros e mulheres negras. Ao observar tal condição, corrobora-se irrestritamente com a autora de que o racismo "rebaixa" a condição de sexo.

\section{RELAÇÕES SOCIAIS DE RAÇA}

Segundo Davis (2016), a associação que foi estabelecida entre as mulheres negras e os serviços domésticos não é um mero vestígio do período da escravidão designado a desaparecer com os anos. Há algo muito problemático e enraizado que precisa ser discutido. Citando a história de uma trabalhadora doméstica do estado da Geórgia (EUA), a autora relembra o arquivo " $A$ documentary history of the negro people in the United States", produzido por um jornalista americano em 1912, no qual foi possível averiguar a péssima situação econômica das mulheres negras ao longo do tempo. Constatou-se que mais de dois terços das mulheres negras foram "convidadas" a encontrar empregos como cozinheiras, lavadeiras, camareiras, babás e zeladoras e acabaram percebendo que estavam em condições tão ruins, se não piores, do que nos anos da escravidão (Davis, 2016). O que se viu no Brasil nada mais foi do que uma reedição dessa segmentação. Levando em consideração as devidas peculiaridades, conforme destacado por Munanga (2006), a predominância das mulheres negras em ocupações como a de empregada doméstica atesta o estabelecimento histórico de uma divisão racial do trabalho. Nesses termos, problematizar tais constatações é algo imprescindível.

Ao considerar o trabalho como momento "privilegiado" da práxis, uma vez que sintetiza as relações estabelecidas entre a natureza e os homens e destes entre si, cria-se a via por excelência em que se processa o descobrimento da posição real que as ordens históricas capturam na completude dialética da sociedade capitalista e das interações mantidas com o todo social. Por conseguinte, torna-se necessário questionar se as mulheres negras, enquanto membros de um grupo muitas vezes visto como submisso e dependente, estariam sujeitas a quais condições em busca de sua integração social (Saffioti, 2013). A origem do que se entende hoje por "trabalho doméstico" está diretamente ligada ao período escravocrata. É nesse contexto que se institui o discurso discriminatório e aos negros é atribuído um trabalho tido como submisso, adequado aos "racialmente inferiores" e de baixa "aptidão intelectual", surgindo a figura dos empregados domésticos. Esse posicionamento dos indivíduos em seu "devido lugar", discursivamente justifica as demandas escravocratas e colonialistas (Conceição, 2009; Teixeira, 2015).

$\mathrm{Na}$ esfera das práticas sociais cotidianas foi sendo disseminada a "cordialidade racial", uma espécie de tolerância com reservas, vinculada ao patrimonialismo e ao clientelismo nas relações sociais. Tal "cordialidade" das relações sociais é fruto da estabilidade brasileira das hierarquias e desigualdades raciais, tomada para enfraquecer eventuais tensões. No entanto, tais vínculos cordiais são o produto de padrões de "[...] $]$ sociabilidade que estabelecem uma reciprocidade assimétrica que, uma vez rompida, justifica a "suspensão" do trato amistoso e a adoção de práticas violentas" (Sales, 2006, p. 230). Como exemplo, ao falar de "complexo de Tia Nastácia", Sales (2006) discute o contexto de uma famosa personagem da literatura infantil, e que poderia ser uma personagem desta pesquisa. Fazendo alusão à personagem dos contos do Sítio do Picapau Amarelo de Monteiro Lobato, o autor explicita que o termo reflete cordialidade, clientelismo e patrimonialismo, questões que sustentam o discurso de que as empregadas domésticas são "quase da família". O "quase" nunca muda de configuração e abre espaço para tirar eventuais vantagens da trabalhadora, 
mantendo-a com a sensação de que está "próxima da família" mas, ao mesmo tempo, "distante" concreta e simbolicamente.

Em grande medida, essas trabalhadoras sempre estiveram proximamente distantes do contato com a família, conforme atesta a proximidade entre cozinha e o quarto nos fundos da casa. Em alguns casos, a "proximidade" representava, na verdade, uma forma de controle e obediência. A frase "quase parte da família", típica de um discurso da família burguesa, indica que "[...]uma dinâmica discursiva que contribui para a informalidade de seu trabalho e para o próprio não reconhecimento de sua atividade como trabalho" (Teixeira, Carrieri \& Naves, 2014, p. 84). Os discursos da "igualdade" e da "afetividade" e "pertencimento" contribuem para mascarar o distanciamento, marcado por dimensões como sexo, raça e classe (Teixeira, Saraiva \& Carrieri, 2015).

Ao considerar o Brasil como uma espécie de "sociedade de status", depreende-se que há uma contínua relação entre raça e posição social. Nesse contexto, seriam atribuídos aos grupos sociais, também incluindo as classes, os "direitos" a um conjunto de privilégios em relação ao Estado e aos demais grupos (Guimarães, 1997). No âmbito das relações entre os indivíduos, tais prerrogativas de posição estariam resguardadas, por meio de "distâncias e etiquetas", que, diante da cor e da aparência, encontram suas referências fundamentais e as demarcações no espaço social.

\section{ESCOLHAS METODOLÓGICAS}

Orientado por uma epistemologia estruturalista, e diante do objetivo geral apresentado, esta investigação se enquadra no método indutivo, viabilizado por uma abordagem qualitativa de caráter descritivo. Conforme Denzin e Lincoln (2006), no estudo qualitativo, o pesquisador assume o papel de um "bricoleur", que reúne imagens transformando-as em uma colcha de retalhos e essa montagem leva o observador a formar interpretações que tendem a se fundamentar umas nas outras. Assim, há a possibilidade de escolha e combinação das práticas e métodos que se concatenam de forma mais adequada ao objeto e ao contexto. Segundo Creswell (2010), nesse escopo metodológico, em um primeiro momento, o número de participantes não é relevante, pois essa abordagem pressupõe uma seleção proposital de sujeitos, considerando aqueles que ajudem o pesquisador a compreender em profundidade a questão de pesquisa pontuada. Tudo está sujeito à qualidade dos depoimentos coletados, assim como o nível de recorrência e divergência de tais informações.

Nesses termos, foram realizadas seis entrevistas com mulheres que trabalham como empregadas domésticas com carteira assinada em casas de família de classe média alta de Belo Horizonte. A opção por este perfil de sujeitos de pesquisa se deve a ele possibilitar maior complexidade nas relações sociais dentro da casa, já que há um vínculo profissional formal, concreto, associado a todos os aspectos do complexo simbolismo de um cotidiano que é simultaneamente próximo e distante, como apontado por Teixeira (2015). Além disso, como o foco de análise era a atividade de cozinhar, buscou-se por pessoas que, independentemente de suas outras funções laborais, cozinhassem em seu trabalho. Um motivo adicional é que em casas de famílias de classe média alta se encontram inclusive configurações arquitetônicas que redimensionam o que se toma por cozinha, o que se desdobra em estética e práticas distintas da maior parte das cozinhas domésticas.

Em relação à coleta de dados, utilizou-se a fotoelicitação. A fotoelicitação permite evocar memórias, comentários e reflexões que espelham um fluxo de relações sociais (Banks, 2009). Seu uso contribui para que os participantes se sintam instigados a compartilhar suas vivências. A partir desse recurso, as entrevistadas foram convidadas a comentar um conjunto de imagens. Elas deveriam observar fotografias e descrever detalhadamente os significados e sentimentos que nelas se manifestavam, conforme a leitura de cada uma. Assim, ao analisar as Figuras 1, 2, 3 e 4, respectivamente, as entrevistadas pontuaram uma série de modificações estruturais e simbólicas que visualizaram nas distintas formas de apropriação da cozinha. As imagens foram organizadas em 
uma ordem proposital, conforme a sequência a seguir. Além disso, não foi dito previamente qual era o número de imagens que seriam apresentadas, nem mesmo qual seria a próxima. Essa dinâmica contribuiu, decisivamente, para os resultados alcançados.

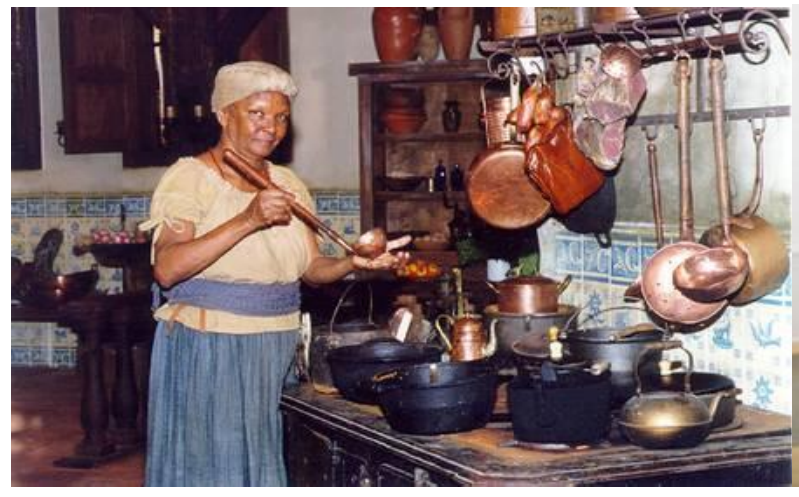

Figura 1 - Fotografia de uma mulher negra cozinhando em uma cozinha antiga Fonte: Disponível em: <http://extra.globo.com/noticias/rio/atriz-chica-xavierque-acaba-de-ganhar-biografia-mae-de-santo-emsepetiba-10596590.html>. Acesso em: 27 mar. 2017

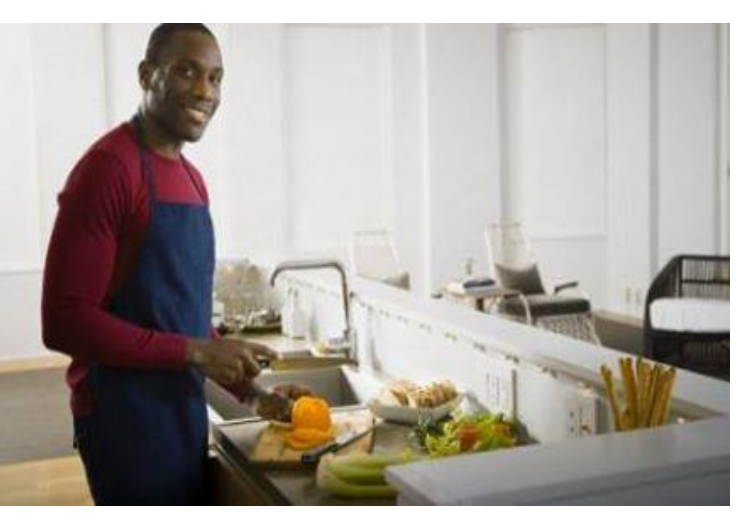

Figura 2 - Fotografia de um homem negro cozinhando em uma cozinha contemporânea Fonte: Disponível em:

<http://valdemartiba.blogspot.com.br/2015/06/truq ues-de-cozinha-para-homens-solteiros.html >. Acesso em: 27 mar. 2017

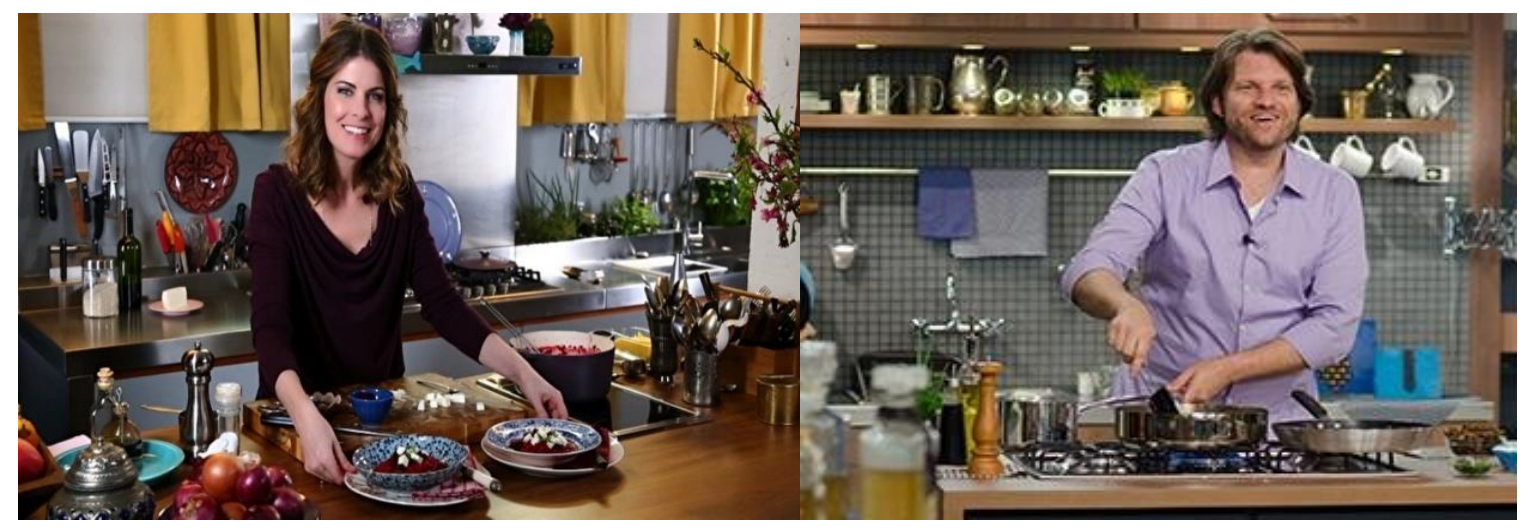

Figura 3 - Fotografia de uma mulher branca cozinhando em uma cozinha contemporânea Fonte: Disponível em:

$<$ http://indicefeminino.com.br/os-chefs-da-tv-eyoutube-rita-lobo/>. Acesso em: 27 mar. 2017
Figura 4 - Fotografia de um homem branco cozinhando em uma cozinha contemporânea Fonte: Disponível em:

<http://www.foxplaybrasil.com.br/watch/16709187 781>. Acesso em: 27 mar. 2017

Cornelsen (2009) pontua que a partir do momento em que se toma consciência de que a linguagem não se resume a um mero recurso instrumental de comunicação, mas que se trata, principalmente, de um elemento constitutivo do que se entende como realidade social, exige-se dos teóricos da área uma atenção a análises mais profundas das narrativas. Logo, inicia-se a compreensão de que os vários usos dos discursos apresentam-se fortemente ligados às organizações (Cornelsen, 2009). Diante das informações obtidas, utilizou-se a Análise Francesa do Discurso como meio de tratamento dos dados. A vertente francesa é propícia aos estudos que consideram aspectos explícitos, implícitos e silenciados nos discursos (Faria, 2009; Fiorin, 2003) e foi utilizada para detalhar ao máximo a fala das sujeitas de pesquisa. As estratégias discursivas de persuasão ideológica empregadas para lidar com os depoimentos foram, de forma não exaustiva: a) análise lexical, na qual foram observados os termos, tempos verbais, enfim os léxicos empregados no discurso; b) condições sociais de produção do discurso, que justificam quais os aspectos concretos dão margem a que o discurso se caracterize da forma como foi enunciado; c) reflexão e refração 
linguísticas, que mostram, respectivamente, aspectos que espelham e que distorcem o real a fim de favorecer a persuasão contida no fragmento discursivo; e d) percurso semântico, que identifica uma forma possível de interpretação dos enunciados discursivos.

A análise identificou categorias discursivas que remetem a quatro territórios: a) o território da "cozinha de verdade", em que cozinhar se relaciona a uma obrigação, e a um cotidiano muitas vezes de melancolia e tristeza; b) o território da "cozinha moderna" como espaço de status social e distinção; c) o território da "cozinha bem montada" enquanto espaço de prazer e alegria; d) o território da "cozinha como vitrine", possibilitando a autopromoção por meio da exposição. A forma de apresentação dos resultados respeita a individualidade das entrevistadas. Já que as entrevistas deram suporte à técnica principal, a fotoelicitação, preservamos os discursos de cada uma das entrevistadas, o que gerou certo nível de repetição que não é de todo mal, já que ele confirma os achados em várias interações distintas. A próxima seção traz os resultados e o conjunto de reflexões que eles propiciaram.

\section{ANÁLISE E DISCUSSÃO}

[Sobre a imagem 1] Ah que legal... é um sentimento bom, um bom sentimento... De estar na cozinha, feliz... Fazendo as coisas que você gosta. Essa aqui é uma cozinha boa, mas hoje o povo gosta mais é daquelas cozinhas chiques, né? Não suja a mão... Então eles preferem (...) [Sobre a imagem 2] Essa aqui é cozinha chique, né? Cozinha linda e maravilhosa, mas eu acho que ele cozinha com mais prazer. Existe muito preconceito... $\mathbf{O}$ Brasil é muito preconceituoso... Eles são preconceituosos em tudo, né? (...) [Sobre a imagem 3] Essa tem cara de patroa... Essa cozinha aqui é cozinha de rico... Milionário, mas assim... Essa cozinha chique não dá pra mim não (...) [Sobre a imagem 4] Haha (risos) Olha o outro... Ele tá mais pra um cozinheiro maravilhoso... É muito interessante ver uma pessoa como ele cozinhando. (Michelle)

É interessante notar como logo de início ela se identifica com a imagem da mulher negra na cozinha, a partir das expressões "que legal" e "um bom sentimento", como um exemplo das práticas simbólicas que atestam afetividade (Saraiva, Carrieri \& Soares, 2014). Muito dessa associação está ligada à infância desta entrevistada no interior da Bahia, o que traz implicações sobre a condição social de produção de seu discurso. A satisfação de Michelle para com a imagem é visível em sua fala. Ao dizer que "[...]hoje o povo gosta mais é daquelas cozinhas chiques[...]", ela deixa um implícito subentendido que esse não é um sentimento por ela compartilhado, sugerindo um distanciamento, estrutural e simbólico do "povo" (Teixeira, Saraiva \& Carrieri, 2015). No trecho "não suja a mão" há um implícito subentendido de que a cozinha da primeira imagem é um lugar em que se suja ao cozinhar.

$\mathrm{Na}$ imagem seguinte, ela exemplificou o que entendia por "cozinha linda e maravilhosa". Se comparada às duas seguintes, na segunda imagem o cenário é mais simples e sem grandes ornamentações; porém, é o suficiente para que Michelle a aponte como um território idealizado. Ela explicita a percepção do preconceito, não ficando claro que ela se refere a um item sexista, racista ou a ambos; mas fica nítido que a raça é um marcador de diferença. Michelle volta a usar "eles", distanciando o seu "grupo" e os demais. Além disso, é possível perceber o percurso semântico da cozinha moderna enquanto fonte de status social e distinção.

Ao tratar da terceira imagem, ela não consegue se perceber cozinhando naquela situação e é explícita ao dizer "essa cozinha não dá pra mim não". Ela não toca na dimensão da raça, mas diz que a personagem se parece com uma "patroa" - não por acaso, branca. Na quarta imagem, por fim, o riso inicial e a fala "[...]interessante ver uma pessoa como ele cozinhando[...]", permitem captar uma refração linguística de homem branco na expressão "pessoa como ele". A apropriação eventual daquele território por um homem branco, assumindo-o como patrão, remete a um conjunto de relações sociais que estão além de um breve cozinhar. Todavia, mesmo com certo estranhamento, ela própria valoriza aquele sujeito enquanto cozinheiro e o define como "maravilhoso". 
[Sobre a imagem 1] Ah... Eu acho que é... Aqui pra mim já era naquele tempo de escravo, não pelo fato dela ser morena, mas é... Aqui não tinha o que nós temos hoje, né? Aqui pra mim... Eu vou te falar que o sentimento que tenho com essa imagem é de tristeza. (...)[Sobre a imagem 2] Aqui pra mim é um momento raro, né? Porque é raro você ver um homem na cozinha. Antes a gente não tinha isso de homem na cozinha... Igual eu falei não tinha isso de homem ir pra cozinha, lavar vasilha, cozinhar... Então aqui é uma satisfação. (...)[Sobre a imagem 3] Aqui é um prazer... Cozinhar em uma cozinha dessa. É uma cozinha que te traz alegria é...Cheia de harmonia, é prazeroso! Ela tá muito feliz e parece ser a dona. (...)[Sobre a imagem 4] Aqui um patrão, né? Porque empregado não é! Se você comparar você vê na daquele outro moço, ele já era um empregado, pois ele estava de avental. Agora o dessa foto, que é um patrão, parece que ele não tem costume não, viu... Eu tenho pra mim que ele foi só ali fazer uma coisinha e pronto. E sobre o sentimento é... Não fiquei muito satisfeita não, porque essa imagem não é uma coisa verdadeira. Essa aqui não é não! De repente, ele tava ali até se mostrando pra alguém, né? Tá ali para fazer uma gracinha e pronto. (Bruna)

Ao contrário de Michelle, Bruna não associa à primeira imagem os mesmos sentimentos. A palavra "tristeza" sugere que a imagem a remete ao tempo da escravidão. Não há uma razão que possibilite identificar o que diferencia os discursos, mas Bruna é mais jovem e não teve tanto contato com a cozinha rústica. Além disso, cabe mencionar o modo como ela, uma mulher negra, utiliza o termo "morena" para descrever a personagem, o colorismo. Ficou nítido, durante toda a abordagem, que Bruna tem problemas de se reconhecer como mulher negra, bem como fazer o mesmo ao descrever a atriz, um incômodo ao ver e analisar a imagem.

Ao reconhecer a segunda imagem como "uma satisfação", Bruna reforça o discurso ideológico sexista, pois, segundo ela "a gente não tinha isso de homem na cozinha". Esse trecho também deixa claro, a partir da análise lexical, que ela se coloca como parte da questão, isto é, já teve vivências que a fizeram refletir sobre essa situação. O fragmento discursivo "momento raro" explicita que é incomum ver os homens na cozinha. Pois é apenas eventual a sua presença ali.

Mesmo recriminando a posição quase que exclusiva da mulher à frente da cozinha, Bruna contribui inconscientemente para a manutenção desse imaginário pois, ao observar a terceira imagem, ela diz que é algo prazeroso. A questão em si não se resume ao sentimento de satisfação, mas à rápida associação que Bruna faz entre uma mulher branca e o ato de cozinhar. Surge então o percurso semântico da cozinha enquanto espaço de prazer, sendo essa ideia reforçada com a cozinha gourmet. Fica explícito que ela atribui maior valor a essa cozinha, pois além de desejar cozinhar em um espaço como aquele, ela o associa a um reduto de harmonia e alegria, em contraste com a primeira imagem.

Na quarta imagem, Bruna volta a associar o homem como um sujeito passageiro na cozinha, mas agora ela qualifica como patrão o homem branco da fotografia. É um implícito subentendido a relação entre raça e hierarquia na casa. Além disso, acrescenta o tema da cozinha como espaço de exposição para os outros. Ela diz "de repente ele tava ali até se mostrando para alguém, né?", deixando claro que a cozinha não é somente eventual, como uma vitrine, um meio de autopromoção, corroborando o argumento de gastronomização do cotidiano alimentar (Barbosa, 2012). Ao contrário da segunda imagem de um negro na cozinha, a que ela associa "satisfação", ela diz sobre a quarta imagem: "não fiquei muito satisfeita não". O discurso final de Bruna é esclarecedor ao dizer que a "imagem não é uma coisa verdadeira", é "para fazer uma gracinha e pronto". O fato de ela o classificar sugere claras relações sociais de sexo e raça, pois ao homem é facultada a eventual "escolha" de cozinhar. E, por ser branco, para não se tratar de um empregado.

[Sobre a imagem 1] Um sentimento de prazer? Talvez ela esteja aqui porque ela gosta. Essa é a tradicional, do dia a dia (...) [Sobre a imagem 2] essa imagem me traz um sentimento de vazio... Ah não sei... Eu acho a primeira imagem é mais normal de acontecer porque... É... Pelo fato de ser uma mulher? Pode ser... (...) [Sobre a imagem 3] Essa já é uma cozinha mais requintada, ela tá mais para patroa... essa é uma cozinha pra de vez em quando, essa não é uma cozinha de todos os dias, né? (...)[Sobre a imagem 4] 
((silêncio)) Esse aqui é um chef preparando... É uma cozinha mais moderna... ele parece ser um patrão. (Jussara)

Assim como Michelle, Jussara, ao olhar para a primeira imagem, associa prazer à atividade e ao local, deixando explícito que, para aquela mulher negra, estar na cozinha é algo cotidiano. No entanto, o termo "talvez" deixa implícito que a entrevistada associa a imagem a uma obrigação. Já a segunda fala retoma um discurso sexista: "Me traz um sentimento de vazio" [ver um homem negro na cozinha] e depois "[...] a primeira imagem mais é mais normal de acontecer[...]”, sugerem que o papel central da cozinha é da mulher - do que Jussara se dá conta na sua fala - e a refração linguística de que há algum tipo de anormalidade quando há um homem na cozinha. As falas, a partir da terceira e quarta imagem, novamente associam a raça ao espaço doméstico, pois os dois personagens são brancos e Jussara os associa a patrões. A ideia de uma cozinha mais requintada, porém "de passagem", se faz presente, ao finalizar sua fala designando como "chef" o último personagem. Nesses termos, é impossível desconsiderar que o senso comum cristaliza estereótipos que hierarquizam as pessoas de acordo com o gênero e a raça, sendo seus territórios distintos também. Tal hierarquia se manifesta no discurso de Jussara. Ao fazê-lo, "[...]institui como primeiro degrau de equalização social a igualdade intragênero, tendo como parâmetro os padrões de realização social alcançados pelos gêneros racialmente dominantes" (Carneiro, 2003, p. 119).

[Sobre a imagem 1] Essa é uma imagem de tristeza. Ela está muito triste nessa foto e a cozinha dela também está triste. É muito preconceituosa essa imagem. É uma cozinha bem antiga. (...) [Sobre a imagem 2] Essa está mais superficial, não está parecendo que é uma cozinha que funciona mesmo. Não está com cara de uma pessoa que vai cozinhar o que ele está cortando ((risos)), me passando um sentimento de vazio. Não está consistente, não. (...) [Sobre a imagem 3] Essa está alegre, prazerosa, parece que está fazendo uma comida bonita e gostosa. Sentimento de alegria. Ela é a patroa, né? ((risos)). (...) [Sobre a imagem 4] Essa aqui também passa uma satisfação. Ele está com cara de que realmente gosta de cozinhar. Uma cozinha bem montada, eu acho que ele cozinha todo dia, mas ele não está com uma roupa adequada, está sem o avental. Pode ser que ele esteja ali só fazendo um número, só para tirar a foto. Ele tá fazendo pose para a foto. (Fernanda)

Fernanda é a quarta entrevistada. Como Bruna, ela também associa à primeira imagem o termo "tristeza" a partir da assunção de que a personagem "está muito triste" e "a cozinha dela também está". Emerge aqui o percurso semântico da cozinha enquanto obrigação e tristeza. Ao dizer que é uma cozinha antiga e que a fotografia é preconceituosa, o implícito pressuposto é o de que ela associa a imagem à escravidão. A segunda imagem trouxe de novo a expressão "vazio", agora ligada também ao léxico "superficial”. É inegável a relação que as entrevistadas fazem entre a primeira e a segunda imagem, quando a principal distinção ainda é o gênero. A incredulidade de haver um homem negro cozinhando no dia a dia é tão nítida em alguns discursos que enfatiza, de forma crucial, as demarcações a partir do sexo.

Novamente, a terceira personagem (mulher branca) é definida como patroa, sendo reafirmado o percurso semântico da cozinha como fonte de prazer e alegria. Há uma mudança conforme se altera o espaço da cozinha: mesmo que algumas entrevistadas percebam algumas das relações sociais de sexo e raça nas imagens, suas falas contribuem para a manutenção das práticas quando valorizam mais as duas últimas fotografias, mesmo quando fazem restrições. As cozinhas ditas gourmet e seus integrantes - brancos - ganham evidente destaque. Sobre a última imagem, Fernanda inicialmente disse que também remetia a uma satisfação com a tarefa diante da "cozinha bem montada", chegando até a dizer que ele parece com alguém que cozinha todos os dias, mesmo não estando com a roupa adequada. No entanto, em seguida ela diz "pode ser que ele esteja ali só fazendo um número, só pra tirar foto". Ao registrar a "pose para foto", a entrevistada admite a eventualidade da cozinha gourmet como meio de promoção pessoal: ela descreve os significados de 
poder que se apresentam na fotografia, o jogo de apropriação e exclusão referenciado por Agnew (1994).

[Sobre a imagem 1] Essa imagem traz para mim a roça. A época em que nossos pais moravam lá no interiorzão. Eu queria estar ali cozinhando nessa cozinha. Essa senhora parece estar feliz com o que ela vai fazer. (....) [Sobre a imagem 2] Olha gente, que chique! Uma cozinha totalmente diferente. Eu fico feliz com essa imagem. Um homem cozinhando com essa felicidade toda, cozinhando bonitinho (...) [Sobre a imagem 3] Que é isso?... (silêncio), essa aqui que é a tal da cozinha gourmet. Ai... O que é isso? Não estou entendendo essa cozinha toda arrumada. Parece meio falso, estranho. Essa mulher não tem nem cara de que cozinha. O prato foi posto ali para ela tirar uma foto. É uma cozinha fictícia, ela está estranha, parece ser a patroa. (...) [Sobre a imagem 4] Fazendo bagunça, nem está prestando atenção no que está fazendo. Não sabe nada. Essa é falsa igual à outra. Ele nem está olhando para a panela, quem cozinha olha para a panela. Não está com cara de que está cozinhando, está parecendo que ele está brincando ali para tirar uma 'fotinha' para postar no Facebook. (Tereza)

Tereza, assim como Michelle, possui um sentimento melancólico em relação à primeira imagem, saudade de "cozinha da roça", e da vida no interior. O tema da "saudade" pode ser observado quando ela cita os pais, a roça, o "interiorzão" e a vontade de se apropriar daquele território (Bernardo, 2015). A mudança para a segunda imagem trouxe algo de surpreendente, ao ver uma figura masculina na cozinha: "olha gente, que chique!". Quando ela diz "[...]um homem cozinhado com essa felicidade toda, cozinhando bonitinho[...]", sugere surpresa por esta ser uma tarefa não-masculina, evidenciando a divisão territorial entre homens e mulheres nas residências (Heredia, 1979). A dinâmica das relações sociais de sexo aparece novamente, naturalizando o trabalho doméstico como feminino (Neves, 2013), mas nenhuma palavra é enunciada a respeito de o personagem ser um homem negro.

Após dizer "o que é isso?" e se manter em silêncio por um bom tempo, Tereza demonstra um estranhamento para com a terceira imagem. Ela percebe que é uma cozinha gourmet, mas não entende porque está "toda arrumada". O implícito subentendido é que tamanha organização não procede em uma "cozinha de verdade", sendo aquela uma "cozinha fictícia". A imagem, de mulher branca, que ela qualifica como patroa, e a disposição dos utensílios, são vistas como uma encenação. Tereza reforça que há uma espetacularização do ato de cozinhar para fins de promoção e exposição em mídias sociais, algo explícito quando se refere à quarta imagem, e reforçando a ideia de que há uma valorização do ato de cozinhar pela construção e apropriação do território gourmet. O termo "brincando" explicita a dinâmica territorial na imagem, uma apropriação que reflete práticas simbólicas passageiras e oportunistas. Por fim, a última fala do grupo das empregadas domésticas é a de Joana.

[Sobre a imagem 1] Essa não é da minha época não... Me traz um sentimento bom, eu acho. Ela cozinha todo dia. (...) [Sobre a imagem 2] Essa é interessante, né? ((silêncio)) Não é muito comum... Muito fácil de ver (...) [Sobre a imagem 3] Essa é chique... Ela está aqui nessa cozinha chique cozinhando, tem esses pratos chique... Ela dá mais vontade de cozinhar porque é mais chique. Essa mulher deve estar só se mostrando, deve ter empregada (...) [Sobre a imagem 4] Esse é famoso... Cozinheiro famoso. Chef. Eu gosto de ver ele cozinhando, me traz um sentimento bom. Ele também deve ter empregada, parece que está ali só para o programa. Essa cozinha é mais importante, mais valorizada. (Joana)

Joana foi a entrevistada que mais refletiu sobre as questões colocadas nas entrevistas, o que ficou nítido após observar olhares, diversos silêncios, respostas confusas e uma constante inquietação após cada pergunta, como se ela as assimilasse e as relacionasse ao seu cotidiano. Ela inicia sua fala colocando-se fora daquele tempo, mas relacionando a imagem da mulher negra na cozinha a um "sentimento bom". Ela analisa as relações de sexo quando diz que a primeira personagem "cozinha todo dia" e que "não é muito comum" ver homens na cozinha (segunda 
imagem). Novamente, fica estabelecida uma dinâmica de submissão (Agnew, 1994) ainda estando ligada apenas à dimensão do sexo.

Em seguida, Joana se interessa pela cozinha das duas últimas imagens: a palavra "chique", dita várias vezes, explicita a valorização desse tipo de cozinha. Além de explicitar que a cozinha gourmet apresentada é "mais importante, mais valorizada", ela associa à valorização uma questão racial: a presença de figuras que não são empregados. A entrevistada contribui para a manutenção do discurso que a diminui enquanto trabalhadora, pois cozinhas em que há apenas empregados (negros) são menos importantes do que cozinhas em que há patrões (brancos). Isso reforça o sistema de hierarquização pontuado por Carneiro (2003) e o sistema de "qualificação" da cozinha ressaltado por Barbosa (2012), pois a própria Joana, subalternizada pelas relações sociais de sexo e raça (Davis, 2016), valoriza o conjunto de referências que a diminui enquanto parte integrante do território.

\section{CONSIDERAÇÕES FINAIS}

Este artigo foi construído em torno do objetivo de identificar e analisar os territórios da cozinha sob a ótica de empregadas domésticas. Para tanto, a partir de uma epistemologia estruturalista, foi empregado o método indutivo com base em um estudo qualitativo de caráter descritivo, no qual foi usada a fotoelicitação para a coleta de dados e a análise do discurso para tratar das falas de empregadas domésticas. Os principais resultados sugerem territorialidades que podem ser classificados em dois grandes grupos: o primeiro assume a cozinha a partir das práticas simbólicas de afetividade, e o segundo que se refere à cozinha como fonte de autopromoção.

Quando se observa a territorialidade na cozinha baseada na afetividade, é curioso o modo como as entrevistadas, enquanto empregadas domésticas, ora se distanciam e ora se aproximam dos significados por elas associados à Figura 1. Há uma familiaridade maior com essa imagem, o que pode ser explicado pela presença de uma mulher negra, pelas vivências relatadas e pela simplicidade da imagem, possivelmente próxima do próprio meio no qual se situam. Todavia, também se observaram saudosismo e rejeição, pois enquanto algumas entrevistadas associaram a imagem a boas lembranças, outras a ligaram aos tempos de escravidão. Isso sugere que o trabalho doméstico e seu contexto de obrigação, principalmente para mulheres negras, estejam associados a todo um sistema concreto e simbólico de aviltamento dessas mulheres a pessoas "quase da família" (Teixeira, Saraiva \& Carrieri, 2015) é fonte de sofrimento - daí a rejeição.

Tais territórios estão amparados no que Pagès et al. (1987) denominaram de sistemas de referência. Nesse sentido, a idade das entrevistadas precisa ser considerada como um fator de distinção entre os discursos, dado que as mais novas demonstraram certa relutância em descrever as primeiras imagens. Todavia, independentemente da impressão causada pela primeira imagem, as entrevistadas estabelecem um nível de ligação com ela, seja a partir do sentimento de pertencimento, ou a partir do de angústia por saber que poderiam (ainda) estar naquela situação. Uma cozinha "de verdade", assim, encerra várias significações de cunho afetivo. Nela, cozinhar para estas mulheres não é opcional: trata-se de uma obrigação cotidiana, o que, muitas vezes, faz com que esse território seja associado a uma melancolia imprecisa associada a uma tristeza pela perda de uma cozinha semelhante, idealizada em algum lugar do passado.

O segundo grupo de territorialidades identificado se baseia na cozinha como espaço de autopromoção. Há um inegável encantamento da maior parte das entrevistadas com as cozinhas apresentadas nas Figuras 2 e 3. Ao mesmo tempo em que se nota um nível de estranhamento com tamanha organização e limpeza do espaço, ficam nítidos, para a maioria delas, a idealização e o desejo pela posse daquelas cozinhas. Algumas chegam a hierarquizar os personagens, mas sem grandes problematizações para além das expressões de inquietação presentes nos discursos, como o sistemático preconceito. Tais cozinhas modernas, por serem bonitas, iluminadas, espaçosas, repletas de utensílios, não casualmente são caras; e, ao serem caras, são acessíveis apenas aos que dispõem 
de recursos para adquiri-las. Isso as faz automaticamente lugares de distinção - dos que não podem possuí-las - e de status social aos que as possuem.

O que torna interessante a descrição das figuras 2,3 e 4, principalmente as duas últimas, é valorização do espaço da cozinha. Em alguns casos, isso é explícito, quando se atribui o adjetivo "chique", ao passo que também ocorre de forma mais velada, como na demonstração de satisfação com o que é retratado. Mesmo não dispondo dos recursos financeiros necessários para construção de uma cozinha gourmet e para a compra de seus utensílios, a maior parte das entrevistadas formula, a partir de seu discurso, como seria a sua cozinha ideal. Aos personagens brancos, proprietários "naturais" da cozinha bem montada, não seria esperada outra coisa senão a associação desse espaço ao prazer. Isso é esperado considerando que não parece haver o "peso da obrigação de ter de se cozinhar" todos os dias - o que só vale para elas, empregadas negras desses patrões brancos. As entrevistadas inclusive supõem que eles disponham de empregadas. Como às vezes "passam por ali", sem estarem obrigados a trabalhar ali cotidianamente, é esperado que sejam alegres as suas expressões, e a cozinha gourmet, dessa forma, seja associada ao prazer.

Essa eventualidade da presença na cozinha, aliás, revela outra faceta de sua territorialidade: o seu esvaziamento afetivo que dá lugar a uma superficialidade típica dos espaços em que se encena algo. À medida que tais cozinhas gourmet são "vitrines", tudo nelas passa a estar à venda, dos ingredientes aos procedimentos, dos utensílios aos livros de culinária: tudo tem um preço e é acessível a quem por ele possa pagar. É previsível que o cenário de tal cozinha seja objeto de desejo, e que tudo o que nesse espaço seja encenado ganhe força de produto a ser consumido. Quem usa o espaço se autopromove ao encenar superficial e lindamente uma cozinha-produto, pronta a ser consumida em todos os seus aspectos. Tudo tem preço e pode ser adquirido - mas não o afeto de cozinhar.

As principais contribuições do texto podem ser tomadas no plano teórico e no plano metodológico. Em termos de teóricos, ao trazer a cozinha doméstica ao plano organizacional, criase a possibilidade de compreender uma dinâmica territorial que é objeto legítimo da análise das organizações. Esta, definitivamente não se restringe aos ambientes corporativos, sendo organizacional o que se presta a ser organizado - o que inclui a vida - e, por que não, a cozinha. Em outras palavras, quando consideramos a vida social organizada, os Estudos Organizacionais virtualmente se candidatam como possibilidade de observação e análise da sociedade que se organiza de alguma maneira. Neste caso específico, ao relacionar às temáticas de relações sociais de sexo e de raça à territorialidade, foi possível refletir sobre aos modos de apropriação territorial diante de marcadores de diferença - uma reflexão imprescindível em qualquer contexto organizacional. É possível dizer que o olhar para a interseccionalidade das categorias, sexo e raça permite a problematização de questões que se referem às diferenças, às relações de poder e aos níveis de agência, considerando o posicionamento das sujeitas de pesquisa (Piscitelli, 2008).

Do ponto de vista metodológico, empregar a fotoelicitação é um caminho muito fértil e promissor para qualificar fenômenos organizacionais. Além de "criar pontes" para trabalhar com públicos socialmente marginalizados como empregadas domésticas, por exemplo, pensar em imagens que possam estimular sujeitos de pesquisa a encararem seu cotidiano, a sua disposição nesse contexto e a organização a que estão sujeitos, é extraordinário. Além disso, de forma associada à coleta de depoimentos, trata-se de uma interessante estratégia para sofisticar a metodologia para além do tradicionalismo das pesquisas qualitativas baseadas em entrevistas.

\section{REFERÊNCIAS}

Agnew, J. A. (1994). Territory. In: Johnston, R. J., Gregory, D. \& Smith, D. M. (Eds.) The dictionary of human geography (3. ed.), 746-747. London: Blackwell Publishers.

Banks, M. (2009). Dados visuais para pesquisa qualitativa. Porto Alegre: Artmed. 
Barbosa, L. (2012). Os donos e as donas da cozinha. In: Freitas, M. E. \& Dantas, M. (Orgs.). Diversidade sexual e trabalho, 171-201. São Paulo: Cengage Learning.

Bernardo, P. (2015). Cotidiano no trike e territorialidades na cidade. Dissertação de mestrado, Universidade Estadual de Maringá, Maringá, PR, Brasil.

Carneiro, S. (2003). Mulheres em movimento. Estudos Avançados, 17(49), 117-133.

Conceição, E. B. (2009). A negação da raça nos estudos organizacionais. Anais do Encontro Anual da Associação Nacional de Pós-Graduação e Pesquisa em Administração, São Paulo, SP, Brasil, 33, setembro.

Cornelsen, E. L. (2009). Análise do discurso no âmbito dos estudos organizacionais: uma abordagem teórica. In: Carrieri, A. P., Saraiva, L. A. S., Pimentel, T. D. \& Souza-Ricardo, P. A. G. (Orgs.). Análise do discurso em estudos organizacionais, 21-44. Curitiba: Juruá.

Creswell, J. W. (2010). Projeto de pesquisa: métodos qualitativo, quantitativo e misto (3a. ed.). Porto Alegre: Artmed.

Davis, A. (2016). Mulheres, raça e classe. São Paulo: Boitempo.

Denzin, N. K., \& Lincoln, Y. (2006). Pesquisa qualitativa. São Paulo: Artmed.

Devreux, A. M. (2005). A teoria das relações sociais de sexo: um quadro de análise sobre a dominação masculina. Sociedade e Estado, 20(3), 561-584.

Faria, A. A. M. (2009). Aspectos de um discurso empresarial. In: Carrieri, A. P., Saraiva, L. A. S., Pimentel, T. D. \& Souza-Ricardo, P. A. G. (Orgs.). Análise do discurso em estudos organizacionais, 45-52. Curitiba: Juruá.

Fiorin, J. L. (2003). Linguagem e ideologia (7.ed.). São Paulo: Ática.

Heredia, B. M. A. (1979). A morada da vida, trabalho familiar de pequenos produtores do nordeste do Brasil. Rio de Janeiro: Paz e Terra.

Hirata, H., \& Kergoat, D. (2007). Novas configurações da divisão sexual do trabalho. Cadernos de Pesquisa, 37(132), 595-609.

Lefebvre, H. (2008). Espaço e política. Belo Horizonte: Ufmg.

Lefebvre, H. (1992). A vida cotidiana no mundo moderno. São Paulo: Ática.

Lefebvre, H. (1991). The production of space. Oxford: Blackwell.

Maia, R. S. (2012). Sobre portas, paredes e afetos: casa, territorialidade e identidade entre os segmentos populares. Terra Plural, 6(2), 339-352.

Munanga, K. (2006). Algumas considerações sobre "raça", ação afirmativa e identidade negra no Brasil: fundamentos antropológicos. Revista USP, 68, 45-57.

Neves, M. A. (2013). Anotações sobre trabalho e gênero. Cadernos de Pesquisa, 43(149), 404-421. 
Pagès, M., Bonetti, M., Gaulejac, V., \& Descendre, D. (1997). O poder das organizações. São Paulo: Atlas.

Paula, F. C. (2011). Sobre a dimensão vivida do território: tendências e a contribuição da fenomenologia. GeoTextos, 7(1), 105-126.

Pereira, D. C., \& Carrieri, A. P. (2005). Movimentos de desterritorialização e reterritorilização na transformação das organizações. RAE-eletrônica, 4(1), 1-17.

Pinto, A., Nunes, S. M., \& Fazenda, R. (2014). Um estudo sobre a influência do gênero em funções tradicionalmente masculinas e femininas. International Journal on Working Conditions, 7, 17-33.

Piscitelli, A. (2008). Interseccionalidades, categorias de articulação e experiências de migrantes brasileiras. Sociedade e Cultura, 11(2), 263-274.

Raffestin, C. (1993). Por uma geografia do poder. São Paulo: Ática.

Saffioti, H. I. B. (2013). A mulher na sociedade de classes (3. ed.). São Paulo: Expressão Popular.

Saffioti, H. I. B. (2004). Gênero, patriarcado, violência. São Paulo: Fundação Perseu Abramo.

Sales, R. (2006). Democracia racial: o não-dito racista. Tempo Social: Revista de Sociologia da USP, 18(2), 229-258.

Santos, M. (2008). Metamorfoses do espaço habitado (6a. ed.). São Paulo: USP.

Saraiva, L. A. S., Carrieri, A. D. P., \& Soares, A. D. S. (2014). Territorialidade e identidade nas organizações: o caso do mercado central de belo Horizonte. Revista de Administração Mackenzie, 15(2), 97-126.

Teixeira, J. C. (2015). As artes e práticas cotidianas de viver, cuidar, resistir e fazer das empregadas domésticas. Tese de doutorado, Universidade Federal de Minas Gerais, Belo Horizonte, Minas Gerais, Brasil.

Teixeira, J. C., Carrieri, A. P., \& Naves, F. (2014). Uma "preta sem cor": a invisibilidade do trabalho doméstico refletida em uma história de vida. In: Naves, F. (Org.) Trabalho e trabalhadores nas sociedades contemporâneas: outras lentes sobre invisibilidade construídas 81-100. Rio de Janeiro: Elsevier.

Teixeira, J. C., Saraiva, L. A. S., \& Carrieri, A. P. (2015). Os lugares das empregadas domésticas. Organizações \& Sociedade, 22(72), 161-178.

Data da submissão: 14/05/2017

Data de aceite: 07/07/2017 